\title{
In Vivo Effects of Agkistrodon rhodostoma Venom: Studies with Fibrinogen $-{ }^{131} I^{*}$
}

\author{
E. Regoeczi, $\dagger$ J. Gergely, $\$$ and A. S. McFarlane \\ (From the National Institute for Medical Research, Mill Hill, London, England)
}

Recently Reid and co-workers described a defibrination syndrome occurring in patients bitten by the Malayan pit viper, Agkistrodon rhodostoma $(1,2)$. The clotting defect, which could last as long as 14 days, was accompanied during the first 3 to 4 days by hemoptysis, discoid ecchymoses, and gum bleeding, and the blood either did not coagulate at all or produced only a poor and abnormal network of fibrin. Platelets were largely reduced in numbers, the one-stage prothrombin time was indefinitely prolonged, and the fibrinogen concentration in the plasma, as estimated by clotting with thrombin, by salting out, or by electrophoresis, was greatly reduced. Infusions of blood or fibrinogen solutions brought about only temporary improvement. Ultimately plasma fibrinogen levels returned to normal, the time required being significantly reduced if specific antivenin was given. Similar fibrinogenopenia was observed by Ghitis and Bonelli (3) in a child bitten by a Bothrops atrox (Columbia).

No conclusive evidence has so far been obtained about how the venom actually establishes the hypofibrinogenemia. By the time victims reach a medical center, defibrination is complete. As was pointed out by Reid, Chan, and Thean (2), any one of several theoretical explanations is possible, viz., suppression of fibrinogen synthesis, direct fibrinogenolysis, activation of the fibrinolytic system, or conversion of fibrinogen into fibrin. Since Plagnol and Martin (4) have shown the venom to comprise a mixture of coagulant and

* Submitted for publication November 18, 1965 ; accepted April 7, 1966.

Some preliminary data on this subject were presented to the $\mathrm{X}$ th Congress of the International Society of Hematology in Stockholm, September 1964.

$\dagger$ Address requests for reprints to Dr. E. Regoeczi, National Institute for Medical Research, Mill Hill, London, N. W. 7, England.

$\$$ Visiting scientist. Present address: Research Institute of the National Blood Transfusion Center, Budapest, Hungary. anticoagulant enzymes, it should clearly be possible to analyze these alternative explanations in terms of enzymes in the venom acting alone or in combination.

In this paper experiments in which Agkistrodon rhodostoma venom (ARV) was given to rabbits that had previously received fibrinogen-131 I will be described, and evidence will be presented which supports the view that the venom acts by rapidly converting intravascular fibrinogen into microclots, which become temporarily trapped in the smaller vessels of various organs. This process is characterized by the disappearance of most of the fibrinogen-131 I activity from the circulation within a short time. Because of the accompanying extensive fibrinolytic reaction, the microclots are rapidly lysed, but their presence in the tissues can be demonstrated histologically in the early stages of the poisoning or by radioautography, and also indirectly, i.e., by using a double-isotope technique. It will also be shown that the effects produced by injecting the chromatographically isolated fibrinolytic fraction of the venom are far from being quantitatively equivalent to those produced by the unfractionated venom.

\section{Methods}

Animals. Male Sandylop rabbits of Mill Hill strain with weights varying between 2.5 and $3.8 \mathrm{~kg}$ were used. They were kept separately in metabolic cages and received a standard pelleted diet and drinking water containing $0.005 \% \mathrm{NaI}$ and $0.45 \% \mathrm{NaCl}$. In a few comparative experiments male rats of a black and white hooded strain were also used.

Radioactivities. Carrier-free ${ }^{125} \mathrm{I},{ }^{131} \mathrm{I}$, and ${ }^{132} \mathrm{Te}$ (from which ${ }^{132} \mathrm{I}$ was eluted) were obtained commercially. ${ }^{1}$

Snake venom. Samples of crude ARV were supplied ${ }^{2}$ in the form of yellow crystals obtained by drying the native venom over silica gel. With solutions of various neutral salts with ionic strengths ranging between 0.1

\footnotetext{
1 Radiochemical Centre, Amersham, England.

2 By Drs. H. A. Reid, K. Chan, and Deveraj, Snake and Venom Research Institute, Penang, Malaya.
} 
and $0.7,65 \%$ of this material could be dissolved. For in vivo purposes venom in $0.95 \% \mathrm{NaCl}$ solution was used. These solutions were kept at $0^{\circ} \mathrm{C}$, and no loss of biological activity was detectable after 6 to 8 months' storage. In each experiment $13 \mu \mathrm{g}$ venom per $\mathrm{kg}$ body weight was injected iv. Since this type of ARV contains a variety of proteins, it will be referred to as "crude ARV." Venom fractions were also obtained by ion exchange chromatography of the crude substance on DEAE-Sephadex A $50^{3}$ by methods described elsewhere (5).

Specific antivenin. The neutralizing capacity of specific antivenin ${ }^{4}$ was such that $0.2 \mathrm{ml}$ prevented any clot formation after mixing $1 \mathrm{ml}$ rabbit plasma with 20 to $50 \mu \mathrm{g}$ crude venom.

Fibrinogen preparations. Two types of fibrinogen were used: a) for in vivo studies, fibrinogen was separated from citrated rabbit plasma with ammonium sulfate as described by McFarlane $(6) ; b$ ) for measuring fibrinolytic activity on fibrin plates, fibrinogen was prepared from a large bulk of fresh human plasma that was first deprothrombinized with barium sulfate as described by Hjort (7), then precipitated with ammonium sulfate at 25 and again at $23 \%$ saturation. The final precipitate, which contained approximately $90 \%$ clottable protein, was dissolved in $0.3 \mathrm{M} \mathrm{KCl}$. After removal of traces of ammonium sulfate by dialysis against the same solvent at $2^{\circ} \mathrm{C}$, a stock comprising one-half of the preparation was kept frozen as a $1 \%$ solution for later experiments. The other half was purified from plasminogen by Mosesson's procedure $(8)$, i.e., by repeatedly precipitating the fibrinogen at $0^{\circ} \mathrm{C}$ from a $0.1 \mathrm{M}$ solution of $\epsilon$-aminocaproic acid 5 $(\epsilon-\mathrm{ACA})$ at an ionic strength of 0.3 with ethanol at a final concentration of $7 \%$. Traces of trapped $\epsilon$-ACA were finally removed by passing the fibrinogen solution through a Sephadex G-25 column at a bed/sample volume ratio of $7: 1$. Fibrin plates poured from this fibrinogen showed no lysis when incubated with urokinase (up to 1,000 Ploug $U$ ) at room temperature or at $37^{\circ}$. C for 48 hours.

Albumin preparations. Rabbit albumin was prepared either by precipitating rabbit plasma with $10 \%$ trichloroacetic acid (TCA) and extracting the albumin with $80 \%$ acetone as described by Schwert (9) or by ion exchange chromatography of rabbit serum on carboxymethyl cellulose (10).

Iodinations. The iodine monochloride method (11) was used. Substitution ratios for fibrinogen were between 0.28 and 0.52 atom iodine per molecule of protein, assuming the molecular weight of the fibrinogen preparation to be 330,000 , and for albumin between 0.35 and 0.60 atom. Nonprotein radioactivity was removed by dialysis in the case of fibrinogen and by anion exchange on De-Acidite $\mathrm{FF}^{6}$ (100 to 200 mesh, chloride form) in the case of albu-

3 Pharmacia, Uppsala, Sweden.

4 Obtained from the Science Section of the Thai Red Cross.

5 Light \& Co., Colnbrook, England.

6 Permutit, London, England. min. The proportion of unbound radioactivity in all preparations was below $1 \%$. Only freshly prepared fibrinogen was iodinated, and the radioactive protein was injected immediately after dialysis.

Measurement of nonprecipitable radioactivities. To the plasma samples was added an equal volume of $20 \%$ (wt/vol) TCA, and after 10 minutes the mixture was centrifuged and the supernatant counted. When less than $0.2 \mathrm{ml}$ plasma was used, or in the case of iodinated protein solutions, inactive carrier albumin was added to ensure at least $8 \mathrm{mg}$ protein per $\mathrm{ml}$ of mixture.

Blood sampling. All samples were collected into test tubes containing $5 \mathrm{mg}$ EDTA- $\mathrm{Na}_{2}$ and $1 \mathrm{mg}$ crystalline soybean trypsin inhibitor ${ }^{7}$ (SBTI) for each $\mathrm{ml}$ of blood, except those for measuring fibrinolytic activity, where SBTI was omitted.

Measuring the clottability of fibrinogen- ${ }^{131} I$ in plasma. Clottability was measured in randomly selected cases as follows : 24 to 48 hours after injecting the fibrinogen- ${ }^{-121} \mathrm{I}$, a plasma sample was taken and the proportion of proteinbound to nonprecipitable radioactivity estimated. Another portion of the same plasma sample was clotted by the method described below, which was also used to estimate plasma fibrinogen concentrations. After several washings with $0.95 \% \mathrm{NaCl}$ solution, the clot was dissolved in alkaline urea and its radioactivity measured. The tests were made in duplicate; clottable radioactivities that were obtained amounted to 94 to $98 \%$ of plasma protein-bound radioactivities.

Estimating plasma fibrinogen concentration. With minor modification Jacobsson's method (12) was used to determine fibrinogen concentration. Of the plasma 1 $\mathrm{ml}$ was diluted with $2 \mathrm{ml}$ of the phosphate buffer (ionic strength $0.144, \mathrm{pH} 6.1$ ) used by Jacobsson and $2 \mathrm{ml}$ distilled water. The latter was used because rabbit fibrin synerizes more readily when the ionic strength of the clotting mixture is kept below the value proposed by Jacobsson for human samples. Fresh thrombin 8 solutions were made up daily in siliconized tubes, and 25 to $100 \mathrm{NIH} \mathrm{U}$ was used per sample. The washed clots were finally dissolved in $7.5 \mathrm{ml} 6.66 \mathrm{M}$ urea in $0.2 \mathrm{~N}$ $\mathrm{KOH}$, and optical densities were measured at $279 \mathrm{~m} \mu$ in a Unicam spectrophotometer. Fibrinogen concentrations were calculated from the specific ultraviolet absorbancy of fibrinogen as described by Jacobsson.

Measuring plasma fibrinolytic activity. The fibrin plate method (13) was used to measure plasma fibrinolytic activity. The ordinary and plasminogen-free fibrinogen stock solutions were diluted with sodium barbitone/

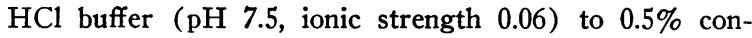
centrations. The plates were clotted with Parke-Davis thrombin that had been previously subjected to gel filtration to remove possible fibrinolytic contaminants. Th:s was done on a Sephadex G-100 column $(96 \times 1.45 \mathrm{~cm})$, the eluent being $0.05 \mathrm{M}$ Tris/ $\mathrm{HCl}+0.3 \mathrm{M} \mathrm{NaCl}, \mathrm{pH} 7.2$, at flow rates ranging between 8 and $9 \mathrm{ml}$ per hour. The optical density of the effluent was continuously re-

7 Worthington Biochemical Corp., Freehold, N. J.

8 Parke-Davis, Detroit, Mich. 
corded at $253 \mathrm{~m} \mu$, and two peaks were visible, the first one having no thrombin activity. However, when plasminogen ${ }^{9}$ was mixed with the thrombin beforehand, it was eluted with this peak. The second one, representing 20 to $24 \%$ of the total protein ultraviolet absorption, contained all the thrombin activity. These fractions were pooled and concentrated by pressure dialysis against $0.95 \% \mathrm{NaCl}$ solution at $2^{\circ} \mathrm{C}$.

The plasma samples to be tested were diluted 20 -fold with distilled water, and the $\mathrm{pH}$ was adjusted to 5.85 (14) with $1.2 \%$ acetic acid. The precipitate was dissolved in a buffer comprising $0.124 \mathrm{M} \mathrm{NaCl}, 0.015 \mathrm{M}$ barbitone, and $0.01 \mathrm{M}$ barbitone sodium at $\mathrm{pH} 7.5$ equivalent in volume to $40 \%$ of the original sample. Threehundredths $\mathrm{ml}$ samples were applied in duplicate to both types of plate, and areas of lysis were recorded after 24 hours at $37^{\circ} \mathrm{C}$.

Prothrombin assay. Owren's method (15) for the assay of prothrombin was used. Rabbit brain thromboplastin (Factor III) was prepared from the gray substance after an exhaustive carotid-jugular perfusion of the cranial vessels of freshly sacrificed animals. Before starting an experiment, two standard prothrombin time curves were plotted for each animal, one before and one after treatment with protamine. The treatment was aimed to remove from the plasma products split from fibrinogen that cause prolongation of prothrombin times and subsequent elimination of the residual protamine by casein precipitation (16). To $0.3 \mathrm{ml}$ plasma was added $0.2 \mathrm{ml}$ of a $0.5 \%$ protamine ${ }^{10}$ solution, and the mixture was centrifuged after standing 1 hour in ice water. Of the supernatant $0.3 \mathrm{ml}$ was mixed with $0.7 \mathrm{ml}$ of a $0.5 \%$ casein solution, and the protamine caseinate was removed by centrifugation after standing 10 minutes at room temperature. The amount of casein required was obtained by preliminary titration of protamine with casein- ${ }^{131} \mathrm{I}$, the protamine/casein ratio chosen being adequate to ensure an excess of casein in all cases. Of the supernatant 0.2 $\mathrm{ml}$ was used for estimating prothrombin time.

Radioactivity measurements. Total body $\boldsymbol{\gamma}$-radiation was measured in a ring of eight Geiger tubes as described by Campbell, Cuthbertson, Matthews, and McFarlane (17), the bladder being first emptied by catheterization and washed out with $5 \%$ hexamethylenetetramine solution. Values were referred to an initial measurement obtained before the first blood sample was taken. Plasma samples were counted either in a well-type scintillation counter or in a Packard auto-gamma spectrometer. Activities per milliliter were relative to that of an initial sample taken 10 to 15 minutes after injecting the labeled protein. Diffusible radioactivities as measured by TCA precipitation of the plasma were multiplied by the iodide- ${ }^{131} \mathrm{I}$ space factor, and the results were subtracted from total body $\gamma$-radiation values to obtain proteinbound activities in the whole body.

\footnotetext{
${ }^{9} \mathrm{Kabi}$ (Stockholm, Sweden) human plasminogen, grade B, lot Dt F 15.

10 Salmine sulfate, British Drug Houses, Poole, England.
}

The space factor was estimated beforehand by injecting 30 to $40 \mu \mathrm{c} \mathrm{Na-}{ }^{181} \mathrm{I}$ iv. Plasma samples were taken 2 to 4 hours after the injection, and the total body radioactivity was measured and divided by the plasma activity per milliliter at the same time. A mean value for the several samples was calculated. During normal fibrinogen- ${ }^{181}$ I catabolism nonprecipitable radioactivities in the body water are mainly present as iodide ${ }^{131} \mathrm{I}$ (6), so that this method can be expected to provide a close approximation to the total quantity of radioactive breakdown products retained. However, this might need to be qualified when very large amounts of labeled fibrinogen are destroyed in vivo within a short time, since peptides differing in diffusibility from iodide might be present. Additionally, some changes in intravascular space due to formation of microthrombi might also occur. Both these factors, however, will tend to produce spurious overestimates by this method of calculation.

Demonstrating microclots in organs. To confirm that volumes of trapped blood measured in isolated organs were not affected by the particular indicator used, we injected fibrinogen ${ }^{181} I$ and albumin ${ }^{132} I$ together into two normal rabbits. Twenty minutes later the animals were sacrificed with an overdose of pentobarbital sodium and dissected, no special precaution being taken to prevent losses of blood, as these should not affect the ratio of radioactivities. The organs were counted in the ring counter and recounted after at least $10{ }^{132} \mathrm{I}$ half-lives. Activities of the individual labeled proteins present were calculated from the differences in activities before and after disappearance of ${ }^{182} \mathrm{I}$ radiation, and their ratio $(\mathrm{R})$ was expressed as a function of the ratio in a terminal blood sample taken from the heart and main thoracic vessels with the formula, $R=\left(F_{0} / F_{B}\right) /\left(A_{0} / A_{B}\right)$, where $F$ is activity of fibrinogen- ${ }^{131} I$ and $A$ is that of albumin${ }^{132} \mathrm{I}$ in an organ (O) and in unit volume of a reference blood sample (B).

The same procedure was repeated in two rabbits that received crude $A R V$ along with an antifibrinolytic agent 5 minutes after injection of the labeled proteins.

Radioautography and histology. One rabbit was injected with $1,000 \mathrm{U}$ heparin ${ }^{11}$ per $\mathrm{kg}$ body wt and about $700 \mu \mathrm{c}$ fibrinogen-181 followed 10 minutes later by $250 \mathrm{mg}$ per $\mathrm{kg} \epsilon-\mathrm{ACA}$ and $13 \mu \mathrm{g}$ per $\mathrm{kg}$ ARV. Eight minutes after the venom was injected, the animal died, and samples of lung, liver, and kidney were excised immediately and fixed in $10 \%$ neutral formalin. After paraffin embedding, 4- $\mu$ sections were cut. Some were coated with Kodak radioautographic stripping emulsion A.R. 10 ; others were stained by the hematoxylin and eosin method and by methods for identifying fibrin, especially the MSB method (18). The radioautographs were developed after 3 and 6 days' exposure.

\section{Results}

Toxicity of crude $A R V$. In 36 experiments 13 $\mu \mathrm{g}$ ARV per kg body weight proved to be lethal

11 Evans Medical Ltd., Liverpool, England. 
for $25 \%$ of the rabbits. By comparison, there was only one death among 24 rats that were defibrinated with 30 to $40 \mu \mathrm{g}$ venom per $100 \mathrm{~g}$ body wt. There were no outward signs in rabbits of the critical nature of the condition, but massive hemoglobinuria was invariably found in catheter urine within 30 minutes of the injection. In lethal cases death occurred regularly within the sixth and twentieth minutes, the previously suspiciously quiet animal being suddenly overcome by violent tonoclonic cramps that lasted a few minutes and terminated in asphyxia. At autopsy performed within 15 minutes of death, intravascular clots were seen only if death occurred within 10 minutes of the injection; otherwise the blood remained fluid.

In four other rabbits that received $\epsilon$-ACA (250 to $370 \mathrm{mg}$ per $\mathrm{kg}$ ) and in two that received SBTI (16 to $19 \mathrm{mg}$ per $\mathrm{kg}$ ) before the venom, the mortality rate was $100 \%$, and extensive intravascular clotting was noted post-mortem. There were no differences in this respect between $\epsilon$-ACA and SBTI.

Behavior of fibrinogen-131 I in normal rabbits injected with crude $A R V$. Characteristic and reproducible changes in fibrinogen- ${ }^{131} \mathrm{I}$ activities were observed in each of the 12 animals belonging to this experimental group, a typical case being illustrated in Figure 1. Immediately after administration of the venom, protein-bound activities in the plasma fell sharply, the average drop amounting to $70 \%$ (range, 60 to $90 \%$ ) of the radioactivity present just before the venom was injected. This initial response, which was complete within half an hour, was accompanied by decreasing fibrinogen concentration and a marked tendency for the blood to coagulate spontaneously. The latter was reflected in the fact that the early blood samples clotted within 30 to 40 minutes of withdrawal and could be saved only by immediate processing irrespective of the anticoagulant used (citrate, oxalate, EDTA, or heparin). This phenomenon reflects the continuing action of the venom in vitro, since it could be prevented by adding specific antivenin.

For a short period thereafter former proteinbound radioactivity levels in the plasma were partially restored, suggesting that the fibrinogen that had disappeared had not been hydrolyzed. However, the labeled protein that returned to the circulation could not be clotted with thrombin. Of

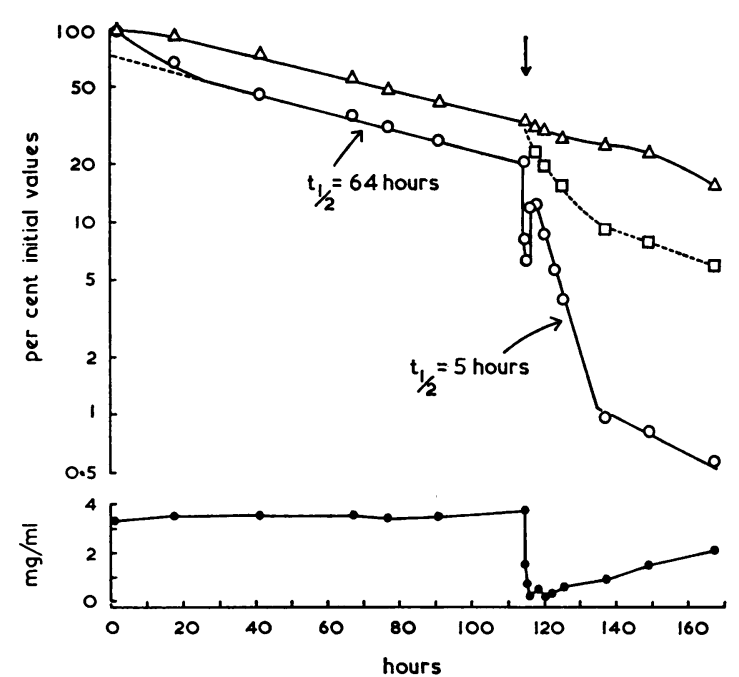

Fig. 1. EFFECT OF CRUDE AGKISTRODON RHODOSTOMA VENOM (ARV) ON FIBRINOGEN- ${ }^{131}$ I TURNOVER. $\triangle=$ total body $\boldsymbol{\gamma}$-radiation; $\square=$ hypothetical total body proteinbound radioactivity; $O=$ intravascular protein-bound activity per milliliter; $=$ plasma fibrinogen concentration. Note three characteristic changes in the curve of intravascular protein-bound radioactivities after the injection of venom at 113 hours (arrow): the rapid initial response, the rebound peak, and the final steep slope.

the radioactivity that disappeared 20 to $50 \%$ reappeared within 2 to 3 hours, after which proteinbound activities began to fall again, this time with a half-life of approximately 5 hours (range, 3 to 8 hours). The occurrence of this rebound peak in intravascular protein-bound radioactivities was seen in all experiments.

Changes in the shape of total body radioactivity curves frequently lagged behind corresponding ones in the intravascular curves. This

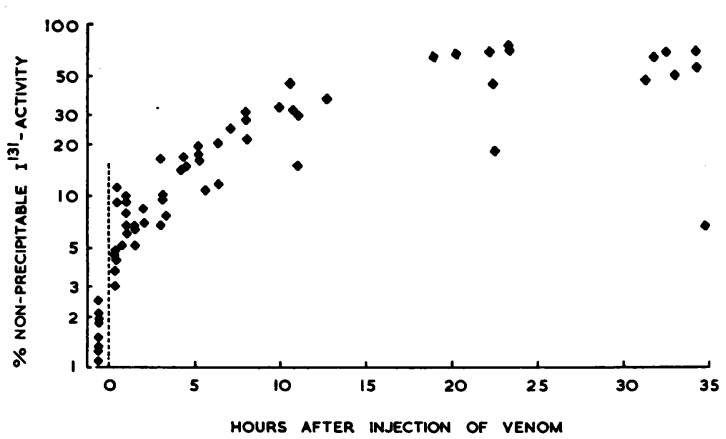

Fig. 2. Diffusible Radioactivities in the plasmas OF 8 RABBITS IMMEDIATELY BEFORE AND AFTER INJECTION WITH ARV. The values are expressed as fractions of total circulating radioactivities. 
is understandable in the first stage of the poisoning, i.e., before the full onset of the fibrinolytic reaction, since as is discussed below the fibrinogen that disappeared was trapped as fibrin in the smaller vessels. However, thereafter the rapidly increasing values of nonprecipitable radioactivities in the plasma indicated, both in absolute and fractional terms, that the rate of liberation of the label from the protein exceeded the renal clearance rate of the breakdown products, thus giving rise to a transient accumulation in the body ( $c f$. Figure 2). This situation is favored by the short half-life ( 5 hours in Figure 1) of the precipitable labeled breakdown products compared with an average total body $t_{\frac{1}{2}}$ of 8.78 hours for iodide- ${ }^{131} \mathrm{I}$ (19). Corrections for the accumulation of diffusible radioactivities were attempted as described under Methods, one example being shown in Figure 1 by the dotted curve. However, as already pointed out, this procedure is based on certain assumptions that may not be valid.

The action of $A R V$ in heparinized animals. Preliminary experiments showed that after intravenous injection of $1,000 \mathrm{U}$ heparin per $\mathrm{kg}$ body wt the blood of normal rabbits would not coagulate for 4 to 5 hours, the samples being observed for up to 24 hours. In two experiments, this dose of heparin was administered 5 minutes before injecting the venom and repeated hourly for 4 hours and then 2 hourly for a further 6 hours. However, the results showed that the levels of circulating fibrinogen-131 I changed with approximately the same speed as in untreated animals (curves A and B in Figure 3).

Experiments on animals with hypoprothrombinemia. Two rabbits were treated with 4 to 8 mg Sinthrome ${ }^{12}$ per day until their prothrombin levels fell to 1 to $2 \%$ of the original value and were then injected with fibrinogen-131 I and 30 minutes later with crude ARV. Again the course of defibrination was the same as in normal animals (curves $\mathrm{A}$ and $\mathrm{C}$ in Figure 3).

Microclot formation and distribution in various organs. Relevant data are summarized in Table I. In the first two columns results from 2 control animals show that the basic assumption underlying the method, namely that the two differently

123 - $\left[\alpha-\left(4^{\prime}\right.\right.$-nitrophenyl) - $\beta$-acetylethyl] -4-hydroxycoumarin, Geigy, Basel, Switzerland.

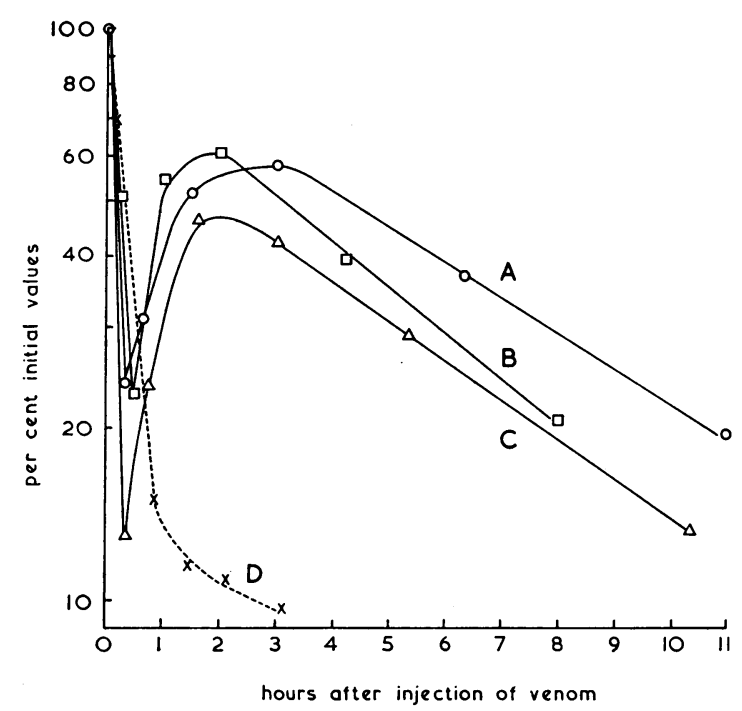

Fig. 3. INTRAVASCULAR PROTEIN-Bound RAdioACtivities IN RABBITS POISONED WITH ARV UNDER DIFFERENT CONDitions. $\mathrm{A}=$ control ; $\mathrm{B}=$ heparinized rabbit ; $\mathrm{C}=\mathrm{rab}-$ bit treated with Sinthrome (prothrombin level $2 \%$ of the starting value); $\mathrm{D}=$ rabbit injected with $\epsilon$-aminocaproic acid + soybean trypsin inhibitor and then slowly infused with diluted venom. For convenience of comparison, values are expressed as percentage of the activity in a plasma sample taken just before the venom was injected. Details of each treatment are described in the text. Differences between curves $\mathrm{A}, \mathrm{B}$, and $\mathrm{C}$ are within the limits of random variations.

labeled plasma proteins have similar volumes of distribution, seems to be justified. Deviations were within $\pm 15 \%$, except for kidneys, liver, eyes, and spleen.

After a single injection of crude ARV, the pattern was greatly changed ( $c f$. rabbits $C$ and $D$ in Table I). The isotope ratio had increased in almost every organ, suggesting an increase in intravascular fibrinogen (or fibrin). In view of the short interval (10 minutes) in which this occurred, it is assumed that large quantities of fibrinogen were clotted and trapped in the vascular bed of the organs. This deposition of fibrin appeared to be nonuniform, relatively high isotopic ratios being found in the lung, muscle, liver, and spleen.

To ensure that the dose of ARV employed did not affect the second marker, we carried out separate experiments by injecting crude ARV or its proteolytic component into rabbits and rats in turnover measurements with albumin-131 I. The 
TABLE I

Isotopic ratios relative to plasma in the organs of rabbits that received a mixture of fibrinogen-131 I and albumin-132I either alone or followed by venom

\begin{tabular}{|c|c|c|c|c|}
\hline \multirow[b]{3}{*}{ Organ } & \multicolumn{4}{|c|}{${ }^{131} \mathrm{I} /{ }^{122}$ I ratio } \\
\hline & \multicolumn{2}{|c|}{ Controls } & \multicolumn{2}{|c|}{ Venom-treated } \\
\hline & $\mathbf{A}$ & B & $\mathrm{C}^{*}$ & Dt \\
\hline Bone marrow $f$ & 1.08 & 1.07 & 3.59 & 1.57 \\
\hline Brain & 0.92 & 1.08 & 2.55 & 2.00 \\
\hline Eyes & 0.82 & 1.05 & 2.89 & 2.67 \\
\hline Fatf & 1.15 & 0.97 & 3.00 & 1.96 \\
\hline Heart & 1.02 & 0.95 & 4.52 & 2.25 \\
\hline Intestine, large & 0.97 & 0.91 & 1.05 & 0.97 \\
\hline Intestine, small & 0.93 & 0.87 & 0.87 & 0.84 \\
\hline Kidney & 1.28 & 1.58 & 1.96 & 1.39 \\
\hline Liver & 1.30 & 1.27 & 3.36 & 4.00 \\
\hline Lung & 0.88 & 0.84 & 10.44 & 10.65 \\
\hline Muscle & 1.07 & 0.95 & 12.63 & 10.96 \\
\hline Skin & 1.05 & 0.98 & 2.34 & 0.35 \\
\hline Spinal medulla & 0.99 & 0.98 & 2.21 & 1.04 \\
\hline Spleen & 1.09 & 1.32 & 13.23 & 10.06 \\
\hline Stomach & 0.95 & 0.99 & 0.95 & 0.80 \\
\hline
\end{tabular}

* Received $380 \mathrm{mg}$ per $\mathrm{kg}$ e-aminocaproic acid a few minutes before the venom.

$\dagger$ Received $16 \mathrm{mg}$ per $\mathrm{kg}$ soybean trypsin inhibitor a few minutes before the venom.

‡ Not collected quantitatively, but representative samples from several sites were assayed. course of plasma and total body radioactivity curves remained unchanged.

Radioautographic and histological findings. Fibrin was readily identified in many capillaries in the alveolar walls of the lung and in a few small venules and arterioles (Figure 4 ) but never, in the specimens examined, in vessels of large caliber. In the liver the distribution of fibrin was focal, small plugs being found sometimes in the sinusoids of a considerable portion of a lobule, whereas in other areas several adjacent lobules were free from material containing fibrin; very occasionally, fibrin was detected in a central vein. In the kidney, small amounts of fibrin were found focally in the capillaries of some glomeruli. None was found in the capsular space or on the surface of the parietal epithelium. Fibrin was also present in a few intertubular capillaries in the cortex and in the renal papilla.

Fibrinogen synthesis in venom-poisoned animals. Since fibrinogen never completely disappeared from the blood of poisoned rabbits, changes

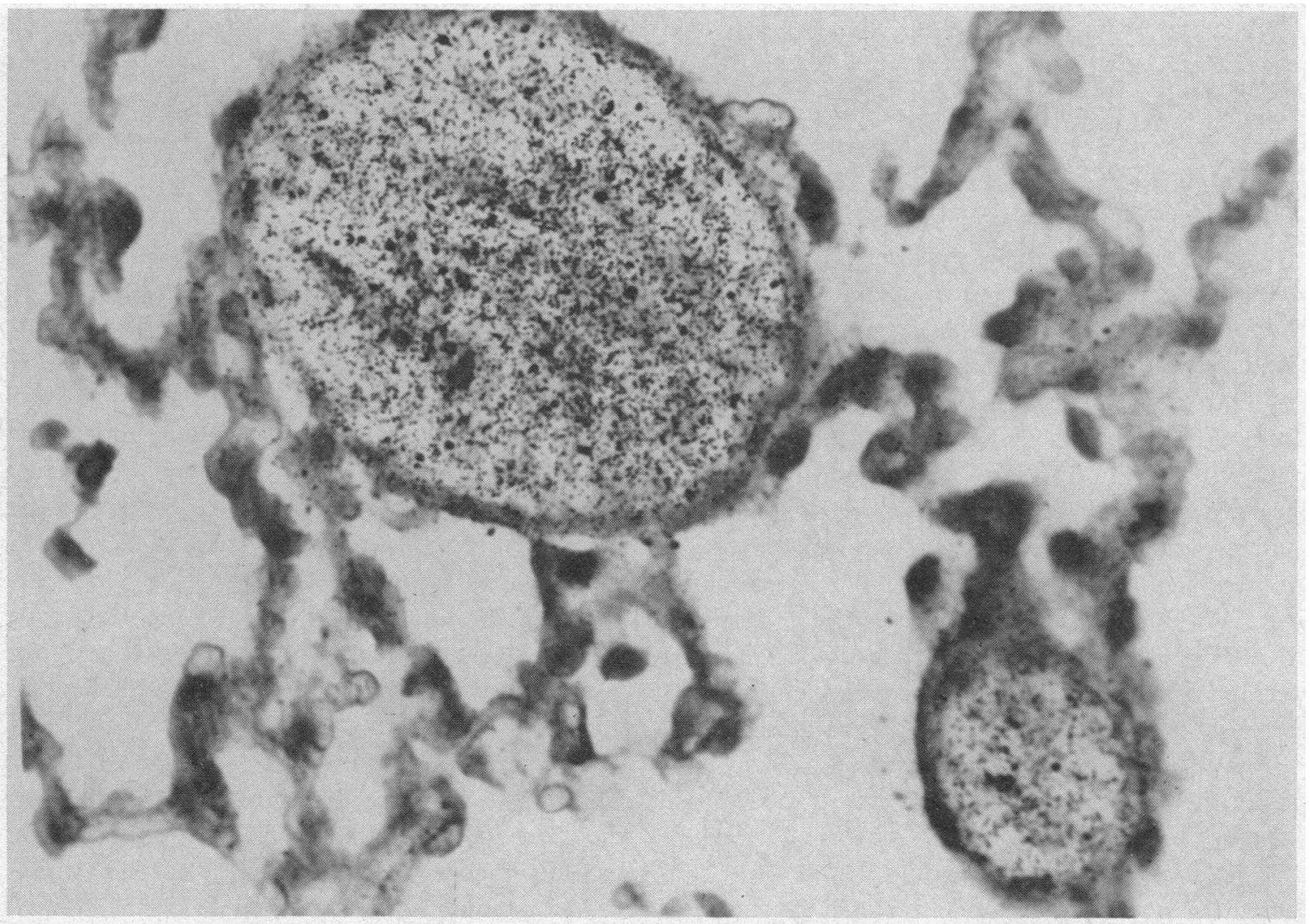

Fig. 4. RAdIOAUTOGRAPH OF A LUNG SECTION FROM A RABBIT THAT RECEIVED FIBRINOGEN- ${ }^{131}$ I FOLLOWED BY VENOM. The silver grains correspond to fibrin plugs that could be seen in the blood vessels. $\times 750$; 6 days' exposure. 
in specific activities of fibrinogen-131 ${ }^{13}$ could be followed throughout the syndrome provided a preparation of sufficiently high specific activity had been given. Such measurements were performed in 5 rabbits, and in each case rapidly decreasing specific activities were observed in the traces of recoverable fibrinogen. This indicates at least qualitatively that the liver continued to synthesize fibrinogen. Quantitative estimates of synthesis rates would be difficult to obtain, however, because of the rapidly changing pool size.

In vitro evidence for increased fibrinogen synthesis rates was seen in 2 rats. These were injected with 20 and $40 \mu \mathrm{g}$ crude ARV per $100 \mathrm{~g}$ body wt, respectively, and sacrificed 1 hour later, by which time the fibrinogen band had disappeared from the electrophoretic patterns of the plasmas. The isolated livers were perfused, and fibrinogen synthesis rates were measured by a leucine- ${ }^{14} \mathrm{C}$ technique (20), the values obtained being 202 and $152 \%$, respectively, of those in normal rat livers.

Action of the isolated fibrinolytic fraction of $A R V$ on fibrinogen in vivo. When crude ARV is applied to a DEAE-Sephadex column in $0.05 \mathrm{M}$

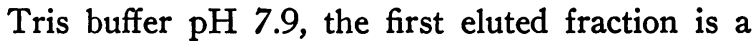
basic protein comprising 30 to $36 \%$ of the total venom protein, and this rapidly hydrolyzes fibrinogen and fibrin in vitro (5). To see whether a similar action is also to be expected in vivo, we performed the following experiments.

Three rabbits were injected intravenously with $4 \mu \mathrm{g}$ of this fraction per $\mathrm{kg}$ body wt (i.e., with an amount equivalent to $13 \mu \mathrm{g}$ crude ARV per $\mathrm{kg}$ ), and the slope of intravascular fibrinogen-131 $\mathrm{I}$, the clottability of the circulating protein-bound radioactivity, and the plasma fibrinogen level were observed during subsequent days. The only change seen was a slight increase in the slope for about 24 hours (Figure 5). These results indicate that the quantity of the lytic fraction injected along with $13 \mu \mathrm{g}$ crude ARV per $\mathrm{kg}$ cannot be significantly responsible for the effects of the venom as described in the foregoing sections.

However, injections of higher doses ( 34 to 770 $\mu \mathrm{g}$ per $\mathrm{kg}$ ) of the same fraction into 4 other rabbits resulted in decreases in plasma fibrinogen concentrations, but corresponding values never fell below $0.7 \mathrm{mg}$ per $\mathrm{ml}$ and returned to normal within 4 to 5 days. Calculations showed that after injection of quantities of the lytic component

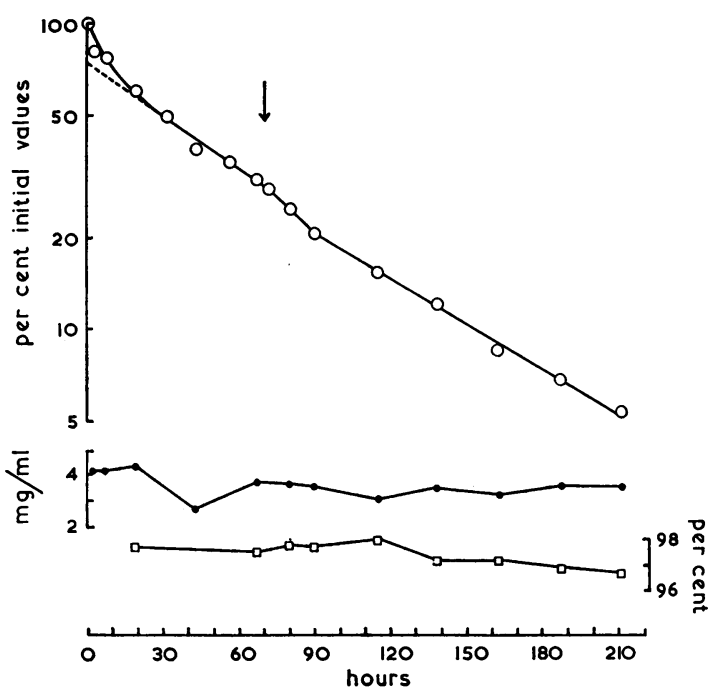

Fig. 5. Failure of the fibrinolytic fraction of the VENOM TO AFFECT THE TURNOVER OF FIBRINOGEN ${ }^{131} \mathrm{I}$. DOSe : $4 \mu \mathrm{g}$ per $\mathrm{kg}$. $\mathrm{O}=$ intravascular protein-bound activity per milliliter ; 0 = plasma fibrinogen concentration $\square=$ clottability of circulating protein-bound radioactivity. Time of injection is marked by an arrow.

equivalent to $150 \mu \mathrm{g}$ crude $\mathrm{ARV}$ per $\mathrm{kg}$ body wt, fibrinogen lost from the plasma pool amounted in 2 hours to approximately $70 \mathrm{mg}$ or $20 \%$ of the intravascular pool. By analogy with relevant observations in vitro (5) it is believed that this effect is due to fibrinogenolysis.

Plasma fibrinolytic activity in venom-treated animals. Changes in fibrinolytic activities in relation to those in plasma fibrinogen- ${ }^{131} \mathrm{I}$ activities were followed up in 3 rabbits after injecting crude ARV. As might be expected, the fibrinolytic activity of the plasma reached a maximum when the protein-bound ${ }^{131} \mathrm{I}$ and fibrinogen concentrations were minimal. However, the onset of fibrinolysis occurred while clotting was still in progress. Subsequently lytic activities gradually decreased, and for some hours no lysis could be observed on plasminogen-free fibrin plates. The values after 24 to 48 hours were again similar to those before poisoning (Figure 6).

Secondary anomalies of the coagulation. Measurements of prothrombin time and thrombin clotting time indicated that in addition to the severe hypofibrinogenemia the plasma of the venomtreated animals exhibited an additional anomaly affecting their coagulability. This is shown in Table II, which gives thrombin clotting times of 


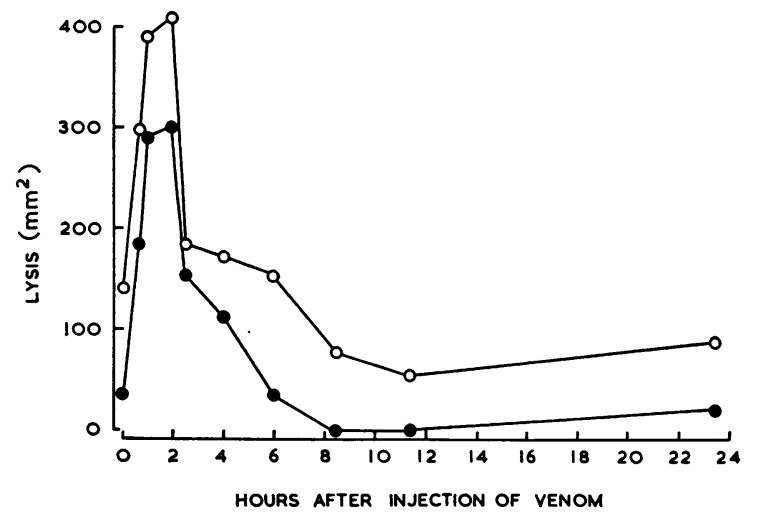

Fig. 6. Fibrinolytic activities of Plasma samples FROM A RABBIT AFTER INJECTION OF VENOM. $O=$ measured by lysis on ordinary fibrin plates; $0=$ measured by lysis on plasminogen-free fibrin plates. (Curve $C$ in Figure 3 relates to the same experiment.)

plasmas with and without fibrinogen supplementation.

The bleeding times were determined by the course of the intravascular fibrinogen-131I curve. Samples 1 and 2 were taken during the initial response to ARV (the latter being close to the minimal point on the curve), samples 3 to 6 all fell within the interval of the rebound peak, and the remaining samples were obtained during the final steep decline.

Thrombin times in system A were prolonged, the first and the last values being moderately so and the rest virtually to infinity. After replacement of fibrinogen the clotting times were normal in samples 1 and 10 in system $B$ and improved in several others (no. 2, 3, and 7 to 9), suggesting that the prolongation in these cases was wholly (no. 1 and 10) or partly due to the reduction in clottable protein. However, adding fibrinogen to the samples that coincided with the peak failed to produce clots. With a stronger thrombin solution in system $C$, some improvement was achieved in the marginal samples (no. 3, 4, and 7), but those coinciding with the maximum of the peak could not be influenced. The same results were obtained with ARV, which is known not to be neutralized by normal serum antithrombin (21), as a clotting agent in system D. A remarkable feature of the virtually incoagulable samples ( $>600$ seconds) in systems B and C was that as early as 20 to 30 seconds after introducing the thrombin very fine fibers could be pulled out although no coherent fibrin network was visible.

The course of changes in prothrombin times could be correlated with ${ }^{181}$ I protein-bound concentrations in a similar manner, the longest prothrombin times being measured during the ${ }^{131} \mathrm{I}$ peak. At this time, prolongations were equivalent to 30 to $50 \%$ of initial prothrombin levels. After removal from the samples of products split from fibrinogen, as described under Methods, prothrombin times were 85 to $90 \%$ of normal.

The origin of the "rebound" peak in the intravascular radioactivity curve. If the venom is infused very slowly intravenously as a dilute solution into an animal that has also received fibrino-

TABLE II

Clotting times of plasma samples from a rabbit at different times after injection of Agkistrodon rhodostoma venom $(A R V)$

\begin{tabular}{|c|c|c|c|c|c|}
\hline \multirow[b]{2}{*}{ No. } & \multirow{2}{*}{$\begin{array}{l}\text { Time } \\
\text { after } \\
\text { ARV }\end{array}$} & \multicolumn{4}{|c|}{ Clotting times } \\
\hline & & System A* & System B† & System Cf & System D\& \\
\hline & hours & \multicolumn{4}{|c|}{ seconds } \\
\hline 1 & 0.33 & 9.5 & 4.6 & & \\
\hline 2 & 0.66 & $>600$ & 9.4 & & \\
\hline 3 & & $>600$ & 240 & 72 & \\
\hline 4 & 1.5 & $>600$ & $>600$ & 260 & \\
\hline 5 & 2.4 & $>600$ & $>600$ & $>600$ & $>600$ \\
\hline 6 & 3.5 & $>600$ & $>600$ & $>600$ & $>600$ \\
\hline 7 & 4.6 & $>600$ & 132 & 27 & \\
\hline 8 & 5.7 & $>600$ & 17 & & \\
\hline 9 & 12.7 & $>600$ & 8 & & \\
\hline 10 & 23 & 45 & 5 & & \\
\hline
\end{tabular}

$* \mathrm{~A}=0.2 \mathrm{ml}$ plasma $+0.2 \mathrm{ml}$ saline $+12 \mathrm{NIH} \mathrm{U}$ thrombin in $0.2 \mathrm{ml}$.

$\dagger \mathrm{B}=$ the same as A but using $0.2 \mathrm{ml}$ of a $0.4 \%$ fibrinogen solution instead of saline.

$\mp \mathrm{C}=$ the same as $\mathrm{B}$ but clotting with $100 \mathrm{U}$ thrombin in $0.2 \mathrm{ml}$.

$\S \mathrm{D}=$ the same as B but clotting with $12 \mu \mathrm{g}$ ARV clotting enzyme in $0.2 \mathrm{ml}$ instead of thrombin. 
lytic inhibitors, survival can sometimes be extended to a few hours. In such cases, the findings are very different in certain aspects from those after a single venom injection. This is shown by data from a rabbit that received a preinjection of $350 \mathrm{mg} \epsilon-\mathrm{ACA}$ per $\mathrm{kg}$ and $10 \mathrm{mg}$ SBTI per $\mathrm{kg}$ and then was infused with $4 \mu \mathrm{g}$ ARV clotting fraction per $\mathrm{kg}$ (equivalent to $13 \mu \mathrm{g}$ crude ARV per $\mathrm{kg}$ ) in $10 \mathrm{ml}$ over 40 minutes. The antifibrinolytic injection was repeated 2 hours after starting the experiment, and its effectiveness was evident from the loss of fibrinolytic activity in plasma samples as demonstrated on fibrin plates. There was clearly no increase in nonprecipitable ${ }^{131} \mathrm{I}$ activities in the plasma, and 98 to $99 \%$ of added fibrinogen- ${ }^{125} \mathrm{I}$ could be recovered from plasma samples as normal clots with $25 \mathrm{U}$ of thrombin, which was also the dose used to clot normal plasmas. Death occurred 3.1 hours after the start of the venom infusion.

The intravascular fibrinogen-131 I curve from this experiment is shown in Figure 3 (curve D), and it is evident that the peak is missing. At autopsy $30.6 \%$ of the injected fibrinogen- ${ }^{131} \mathrm{I}$ activity was present in the lung, $32.5 \%$ in the liver, and $3.9 \%$ in the spleen. These observations lead to the conclusion that the rebound peak in protein-bound radioactivities arises from the body's fibrinolytic response to widespread microclots.

If this is so, then the labeled material representing the peak should consist of "soluble" fibrin and its breakdown products. Indeed, plasma samples taken at this time can be "clotted" without thrombin simply by adding protamine. Since protamine does not split off the fibrinopeptides but is known to promote fibrin polymerization strongly (22), the most likely explanation is that protamine repolymerizes circulating solubilized fibrin (and probably its larger breakdown products) from dissolving microclots. These clots are friable and break easily on winding. At the height of the peak, up to $85 \%$ of the proteinbound ${ }^{131} \mathrm{I}$ in the plasma could be converted into this type of clot with protamine in concentrations between 0.5 and $1.0 \mathrm{mg}$ per $\mathrm{ml}$.

\section{Discussion}

The results indicate that the crude ARV acts by establishing a fibrination-defibrination syn- drome (23), and this conclusion suggests the following general picture. The injected venom after mixing with the plasma immediately attacks circulating fibrinogen, converting the majority of the intravascular pool into fibrin within half an hour. The formation of clots leads to an immediate activation of fibrinolytic enzymes so that their presence in excessive amounts in the blood becomes apparent before defibrination is complete. Probably only microclots form, and those that start in the larger blood vessels soon become trapped in smaller ones. In this way more and more fibrin from the general circulation becomes localized in the capillary networks of the organs, thus giving rise to the kind of distribution of radioactivities shown in Table $I$.

Although the fibrinolytic response is almost instantaneous, the rate of fibrin formation must exceed fibrinolysis for emboli to form at all. Especially in the lungs these present a critical hazard to life, but many of them resolve rapidly, and previously occluded vessels are reopened. In this way significant amounts of noncoagulable labeled protein begin to escape into the circulation, giving rise to a "rebound" peak in the curve of intravascular protein-bound radioactivities as shown in Figures 1 and 3. Anoxia, of embolic origin, may contribute to, or indeed may be primarily responsible for, activation of the fibrinolytic activity of the blood, since plasminogen activator is known to be localized in the vascular endothelium $(24,25)$ and its release is increased after anoxia (26-28).

A similar disappearance and reappearance of protein-bound radioactivities were observed by Adelson (29) using fibrinogen-131 ${ }^{13}$ in dogs after infusing thromboplastin, and it is likely that microclot formation occurred in this case also. Indeed it is possible that curves of intravascular proteinbound ${ }^{131} \mathrm{I}$ activity after fibrinogen- ${ }^{131} \mathrm{I}$ injections similar to those in Figures 1 and 3 are diagnostic of generalized defibrination followed by fibrinolysis.

In spite of dual coagulant and fibrinolytic properties of the unfractionated venom, which can be demonstrated in vitro (5), the in vivo situation can be regarded as primarily due to coagulation for the following reasons: $a$ ) the peculiar distribution of radioactivity in the organs, combined with the microscopic findings, both suggested the presence of microclots $; b$ ) previous administration 
of antifibrinolytic agents, which have no effect on the turnover of fibrinogen- ${ }^{131} \mathrm{I}$ in normal rabbits (30), increased the mortality from 25 to $100 \%$; and $c$ ) quantities of the fibrinolytic fraction of the venom proportional to the dose of crude ARV had little effect on the turnover of fibrinogen-131I and produced no significant changes in the clottability of intravascular ${ }^{131} \mathrm{I}$ activities or in fibrinogen concentrations.

The absence of any demonstrable protective effect of heparinization against clot formation by the venom in vivo agrees well with the conclusion of Nahas, Denson, and Macfarlane (21) that the venom contains a clotting enzyme that acts directly on fibrinogen. The difference between the actions of thrombin and ARV on fibrinogen is also reflected by the fact that the B-chains of fibrin are electrophoretically distinguishable depending on which coagulant is used; furthermore, heparin has no accelerating effect on the inactivation of the venom in vitro (5).

Radioautographic and histological observations agree in establishing the presence of microclots in the smaller vessels of various organs. In conformity with this finding, fibrinogen-131 I/albumin${ }^{132}$ I ratios in many organs were much higher than in the plasma at death. Since these were obtained in animals in which any significant liberation of label from fibrinogen had been prevented with high concentrations of antifibrinolytic agents, accumulation of labeled breakdown products in the surrounding tissues cannot explain them, and it is evident that a large part of the circulating fibrinogen had been retained in coagulated form in the organs.

From values for ${ }^{131} \mathrm{I}$ activities in organs relative to the whole body it should be possible to arrive at a quantitative over-all picture of the distribution of clots. However, as already mentioned, some loss of blood was unavoidable during dissection of the animals, and some tissues were not sampled quantitatively. Therefore, the data obtained unfortunately do not enable us to present a complete picture of the redistribution of ${ }^{131} \mathrm{I}$ activity in the body. Yet, the activity ratios taken in conjunction with relative weights of the individual organs suggest in these experiments that most of the trapped fibrin was present in lungs, muscles, liver, and spleen, and little or no excess ${ }^{131}$ I activity was detectable in the stomach, intes- tines, and skin. No doubt, the reason for this pattern resides in different kinds of vascularization in the different organs, but this is a question beyond the scope of the present investigations.

The appearance of a secondary coagulation anomaly after the full onset of the fibrinolytic response, however interesting per se, probably had little or no significant influence on the main conclusions from the present experiments. Although it is clear that the results of estimating fibrinogen concentration by thrombin clotting became more and more unreliable as clot lysis progressed, other observations (e.g., the extent of the fall in plasma protein-bound ${ }^{131} \mathrm{I}$ activities during the initial response and results of electrophoretic studies) suggest that the majority of the circulating fibrinogen had indeed been converted into fibrin. In clinical situations, however, where the effect of the venom may be less acute and only a fraction of the total intravascular fibrinogen is converted to fibrin, the presence of fibrin polymerization inhibitors may play a much more significant role in the coagulation disorder. The prolonged absorption of small quantities of venom from damaged subcutaneous sites with subsequent continuous production of fibrin breakdown products is a likely explanation for the protracted incoagulability of the blood reported in human victims $(1,2)$.

\section{Summary}

1. The coagulation disorder caused by the venom of the Malayan viper Agkistrodon rhodostoma (ARV) was investigated in rabbits that had previously been injected with ${ }^{131} \mathrm{I}$-labeled fibrinogen.

2. A dual isotope method is described for demonstrating redistribution of ${ }^{131} \mathrm{I}$-labeled fibrinogen presumed to be fibrin microclots in the organs. Radioautographic and histologic examinations of lung, liver, and kidney have confirmed the presence of microclots.

3. Results indicate that fibrin formation with venom caused defibrination syndrome, the extent and dynamics of which were unaffected by preventive heparinization or hypoprothrombinemia. Antifibrinolytic agents invariably caused death when given before the venom.

4. An in vivo study of the fibrinolytic enzyme of the venom, which was isolated by ion exchange chromatography, showed that the presence of 
this component does not nearly account for the great reduction in fibrinogen levels seen after injection of the unfractionated venom.

\section{Acknowledgments}

The authors wish to thank Dr. L. E. Mutschler for performing the liver perfusions, Dr. J. S. F. Niven for the histologic and Mr. M. R. Young for the radioautographic preparations, and Miss B. A. Stannard for technical assistance.

\section{References}

1. Reid, H. A., P. C. Thean, K. E. Chan, and A. R. Baharon. Clinical effects of bites by Malayan viper (Ancistrodon rhodostoma). Lancet 1963, 1, 617.

2. Reid, H. A., K. E. Chan, and P. C. Thean. Prolonged coagulation defect (defibrination syndrome) in Malayan viper bite. Lancet 1963, 1, 621.

3. Ghitis, J., and V. Bonelli. Fibrinogenopenia in snake bite. Ann. intern. Med. 1963, 59, 737.

4. Plagnol, H., and P. Martin. Electrophorèse du venin d'Ancistrodon rhodostoma boie. Ann. Inst. Pasteur 1957, 92, 525.

5. Regoeczi, E. On the dual action of Agkistrodon rhodostoma venom on fibrinogen. Z. Tropenmed. Parasit. 1966, 17, in press.

6. McFarlane, A. S. In vivo behavior of $\mathrm{I}^{131}$-fibrinogen. J. clin. Invest. 1963, 42, 346.

7. Hjort, P. F. Intermediate reactions in the coagulation of blood with tissue thromboplastin. Convertin, accelerin, prothrombinase. Scand. J. clin. Lab. Invest. 1957, 9 (suppl. 27).

8. Mosesson, M. W. The preparation of human fibrinogen free of plasminogen. Biochim. biophys. Acta (Amst.) 1962, 57, 204.

9. Schwert, G. W. Recovery of native bovine serum albumin after precipitation with trichloroacetic acid and solution in organic solvents. J. Amer. chem. Soc. 1957, 79, 139.

10. Peterson, E. A., and H. A. Sober. Chromatography of proteins. I. Cellulose ion-exchange adsorbents. J. Amer. chem. Soc. 1956, 78, 751.

11. McFarlane, A. S. Efficient trace-labelling of proteins with iodine. Nature (Lond.) 1958, 182, 53.

12. Jacobsson, K. Studies on the determination of fibrinogen in human blood plasma. Scand. J. clin. Lab. Invest. 1955, 7 (suppl. 14).

13. Astrup, T., and S. Müllertz. The fibrin plate method for estimating fibrinolytic activity. Arch. Biochem. 1952, 40, 346.
14. Astrup, T., J. Piper, and J. Rasmussen. The fibrinolytic system in human blood, as exemplified in a case of agammaglobulinemia and a case of macroglobulinemia. Scand. J. clin. Lab. Invest. 1960, $12,336$.

15. Owren, P. A. A quantitative one-stage method for the assay of prothrombin. Scand. J. clin. Lab. Invest. $1949,1,81$.

16. Cohn, E. J., and J. T. Edsall. Proteins, Amino Acids and Peptides as Ions and Dipolar Ions. New York, Reinhold, 1943, p. 601.

17. Campbell, R. M., D. P. Cuthbertson, C. M. Matthews, and A. S. McFarlane. Behaviour of ${ }^{14} \mathrm{C}$ - and ${ }^{181} \mathrm{I}-$ labelled plasma proteins in the rat. Int. J. appl. Radiat. 1956, 1, 66.

18. Lendrum, A. C., D. S. Fraser, W. Slidders, and R. Henderson. Studies on the character and staining of fibrin. J. clin. Path. 1962, 15, 401.

19. Regoeczi, E. The renal excretion of ${ }^{131} \mathrm{I}$-iodide in the rabbit. III. Investigations on the fate of the ${ }^{131} \mathrm{I}$ label released by breakdown of iodinated proteins in the rabbit. Pflügers Arch. ges. Physiol. 1963, 277, 76.

20. Cohen, S., and A. H. Gordon. Catabolism of plasma albumin by the perfused rat liver. Biochem. J. 1958, 70, 544.

21. Nahas, L., K. W. E. Denson, and R. G. Macfarlane. A study of the coagulant action of eight snake venoms. Thrombos. Diathes. haemorrh. (Stuttg.) 1964, 12, 355.

22. Godal, H. C. The interaction of protamine with human fibrinogen and the significance of this interaction for the coagulation of fibrinogen. Scand. J. clin. Lab. Invest. 1960, 12, 433.

23. Schneider, C. L. Etiology of fibrinopenia : fibrination defibrination. Ann. N. Y. Acad. Sci. 1959, $75,634$.

24. Todd, A. S. Fibrinolysis autographs. Nature (Lond.) 1958, 181, 495.

25. Warren, B. A. Fibrinolytic activity of vascular endothelium. Brit. med. Bull. 1964, 20, 213.

26. Holemans, R. Origin of blood fibrinolytic activity. Lancet 1963, 2, 364.

27. Tighe, J. R., and H. T. Swan. Fibrinolysis and venous obstruction. Clin. Sci. 1963, 25, 219.

28. Ata, M., P. S. Azeem, and J. R. Tighe. The influence of venous occlusion on the fibrinolytic activity of blood. Clin. Sci. 1965, 27, 357.

29. Adelson, E. Fibrinogen and fibrin, their roles in health and disease. Normal metabolism. Fed. Proc. 1965, 24, 810.

30. Gajewski, J., and B. Alexander. Effect of epsilonaminocaproic acid on the turnover of labelled fibrinogen in rabbits. Circulat. Res. 1963, 13, 432. 